\title{
Action mechanisms involved in the bioprotective effect of Lactobacillus harbinensis K.V9.3.1.Np against Yarrowia lipolytica in fermented milk
}

\author{
Mieszkin Sophie ${ }^{1}$, Hymery Nolwenn ${ }^{1}$, Debaets Stella ${ }^{1}$, Coton Emmanuel ${ }^{1}$, Le Blay Gwenaelle ${ }^{1}$, \\ Valence Florence ${ }^{2}$, Mounier Jérôme ${ }^{1 \text { ? }^{*}}$
}

${ }^{1}$ Université de Brest, EA3882 Laboratoire Universitaire de Biodiversité et Ecologie Microbienne, IBSAM, ESIAB, Technopôle Brest-Iroise, Plouzané, France

${ }^{2}$ STLO, Agrocampus Ouest, INRA, 35000 Rennes, France

*Corresponding author : Jérôme Mounier, email address : jerome.mounier@univ-brest.fr

\begin{abstract}
:
The use of lactic acid bacteria (LAB) as bioprotective cultures can be an alternative to chemical preservatives or antibiotic to prevent fungal spoilage in dairy products. Among antifungal LAB, Lactobacillus harbinensis K.V9.3.1Np showed a remarkable antifungal activity for the bioprotection of fermented milk without modifying their organoleptic properties (Delavenne et al., 2015). The aim of the present study was to elucidate the action mechanism of this bioprotective strain against the spoilage yeast Yarrowia lipolytica. To do so, yeast viability, membrane potential, intracellular $\mathrm{pH}(\mathrm{pHi})$ and reactive oxygen species (ROS) production were assessed using flow cytometry analyses after 3,6 and 10 days incubation in cell-free supernatants. The tested supernatants were obtained after milk fermentation with yogurt starter cultures either in co-culture with L. harbinensis K.V9.3.1Np (active supernatant) or not (control supernatant). Scanning-electron microscopy (SEM) was used to monitor yeast cell morphology and 9 known antifungal organic acids were quantified in both yogurt supernatants using high-performance liquid chromatograph (HPLC). Yeast growth occurred within 3 days incubation in control supernatant, while it was prevented for up to 10 days by the active supernatant. Interestingly, between 66 and $99 \%$ of yeast cells were under a viable but non-cultivable (VNC) state despite an absence of membrane integrity loss. While ROS production was not increased in active supernatant, cell physiological changes including membrane depolarization and $\mathrm{pHi}$ decrease were highlighted. Moreover, morphological changes including membrane collapsing and cell lysis were observed. These effects could be attributed to the synergistic action of organic acids. Indeed, among the 8 organic acids quantified in active supernatant, five of them (acetic, lactic, 2-pyrrolidone-5-carboxylic, hexanoic and 2hydroxybenzoic acids) were at significantly higher concentrations in the active supernatant than in the control one. In conclusion, this study has provided new information on the physiological mechanisms induced by an antifungal LAB that could be used as part of the hurdle technology to prevent fungal spoilage in dairy products.
\end{abstract}




\section{Highlights}

- The action mechanism of $L$. harbinensis bioprotective culture against $Y$. lipolytica was studied. The cell-free yogurt supernatant obtained with the bioprotective culture exhibited a fungistatic effect. Yeast membrane depolarization and pHi decrease were observed. Yeast cell morphological changes were observed. Several organic acids could be responsible for the observed antifungal activity.

Keywords: Lactobacillus harbinensis, Yarrowia lipolytica, Bioprotection, Antifungal, Action mechanisms, Dairy products 


\section{Introduction}

Fungal spoilage, by either molds or yeasts, is a major concern for the food industry. This type of spoilage can occur at any stages of the food production chain and results from fungal growth in the food, leading to an alteration of its organoleptic properties. Molds such as Aspergillus, Fusarium and Penicillium spp. may also produce mycotoxins, which can have adverse effects on human health (Corsetti et al., 1998; Pawlowska et al., 2012; Pitt and Hocking, 2009). Among foods concerned by fungal spoilage, fermented dairy products are not spared with such contaminations, which are caused by acid-tolerant fungi such as Candida, Cladosporium, Debaryomyces, Galactomyces, Mucor, Penicillium, Rhodotorula and Yarrowia spp. (Delavenne et al., 2011; Fleet 1990; Hymery et al., 2014; Mayoral et al., 2005). To prevent fungal spoilage in the dairy industry, a large range of hurdle technologies, such as physical treatments and the use of chemical preservatives or antibiotics such as natamycin, is applied (Davidson, 2001; Schnurer and Magnusson, 2005). However, due to the emergence of strain resistance to these traditional antimicrobial molecules, as well as the rising demand from consumers for minimally processed or preservative-free food, the development of natural alternatives, such as antifungal bioprotective cultures, is gaining more and more interest (Pawlowska et al., 2012).

Among the best candidates, lactic acid bacteria (LAB) are usually reported (Dalié et al., 2010; Delavenne et al., 2012; Schnurer and Magnusson, 2005) and several commercial antifungal LAB cultures are currently available on the market. Indeed, LAB are known to produce active antifungal metabolites that may act in a synergistic manner. Among these metabolites, organic acids, phenolic compounds, hydroxylated fatty acids, phenyllactic acids, hydrogen peroxide, reuterin, cyclic dipeptides or proteinaceous compounds have been identified (Dalié et al., 2010; Schnurer and Magnusson, 2005). LAB are also of great interest due to their natural occurrence and long history of safe use in food, mainly in fermented products. For this reason, 
most of them have a GRAS (generally recognised as safe) status in the United States of America and are included in the qualified presumption of safety (QPS) list in the European Union (Bernardeau et al., 2008).

To date, a few studies have investigated the antifungal properties of LAB in dairy products and especially in fermented milk. Lactobacillus casei AST18 and Lactobacillus plantarum 16 were reported to be efficient bioprotective strains against Penicillium sp. and Rhodotorula mucilaginosa, respectively; while Lactobacillus reuteri INIA P572 and INIA P579, were also selected as potential candidates for fermented milk bio-preservation via reuterin production (Crowley et al., 2012; Langa et al., 2013; Li et al., 2013). LAB isolates obtained from traditional fermented curd/yogurt-like called 'katak' made in Bulgaria, and affiliated to Lactobacillus brevis, have also shown a broad spectrum of antifungal activity against several fungal genera such as Aspergillus, Fusarium, Penicillium and Trichoderma (Tropcheva et al., 2014). More recently, Aunsbjerg et al. (2015) reported the antifungal effect of Lactobacillus paracasei DGCC 2132 against Penicillium solitum and Penicillium salamii in fermented milk. Its activity was associated to diacetyl as well as other unidentified antifungal compounds. Delavenne et al. (2013) showed that Lactobacillus harbinensis K.V9.3.1Np possessed a remarkable antifungal activity in fermented milk preventing the growth of six fungal species (Debaryomyces hansenii, Kluyveromyces lactis, Kluyveromyces marxianus, $R$. mucilaginosa, Penicillium brevicompactum and Yarrowia lipolytica) during 5 weeks of storage at $10^{\circ} \mathrm{C}$. Then, Delavenne et al. (2015) showed that this inhibitory activity was an all-or-nothing phenomenon and that $2.5 \times 10^{6} \mathrm{CFU}$ of L. harbinensis K.V9.3.1Np per gram of fermented milk were necessary to achieve $Y$. lipolytica growth inhibition at the time of contamination. Furthermore, this strain had no negative effect on product organoleptic properties at an inoculation rate of $5 \times 10^{6} \mathrm{CFU} \mathrm{ml}{ }^{-1}$. It is worth mentioning that this antifungal strain is the first one described in the literature to possess an antifungal activity against $Y$. lipolytica. This 
is particularly interesting as this fungal species has been shown to possess a very high resistance to weak acid preservatives, such as benzoic and sorbic acids, in comparison to other spoilage yeasts (Prahailong and Fleet, 1997).

To extend our knowledge regarding the antifungal activity of L. harbinensis K.V9.3.1Np in fermented milk, the present study aimed at understanding the action mechanisms induced by the metabolites released by this bacterial strain on the physiology of $Y$. lipolytica, a yeast species highly resistant to organic acids and commonly involved in dairy product spoilage. After incubation of $Y$. lipolytica cells in cell-free supernatant obtained after milk fermentation with yogurt starters in co-culture with L. harbinensis K.V9.3.1Np. (active supernatant) or not (control supernatant), measurements such as viability, membrane potential, intracellular $\mathrm{pH}$ (pHi) and production of reactive oxygen species (ROS) were performed using flow cytometry. Scanning-electron microscopy (SEM) was used to monitor the yeast cell morphology and the occurrence of 9 known antifungal organic acids were compared in both supernatants. The effects of control and active supernatants on Y. lipolytica cells physiology and morphology were also compared to that of supernatants supplemented with either acetic acid or natamycin (positive controls). These two well-known antifungal compounds were chosen because they exhibit different action modes. Natamycin targets ergosterol in the cytoplasmic membrane (Te Welscher et al., 2008) while acetic acid is a weak organic acid causing intracellular acidification (Stratford et al. 2013 ; Ullah et al. 2012).

\section{Materials and methods}

\subsection{Microorganisms and culture conditions}

L. harbinensis K.V9.3.1Np was previously isolated from cow milk by Delavenne et al. (2012). This strain was kept at $-80^{\circ} \mathrm{C}$ in Man, Rogosa and Sharpe (MRS) broth supplemented with $30 \%(\mathrm{v} / \mathrm{v})$ glycerol and routinely cultivated in MRS broth overnight at $30^{\circ} \mathrm{C}$ before being streaked on MRS agar for purity checking. After sub-culturing in MRS broth for $24 \mathrm{~h}$ at $30^{\circ} \mathrm{C}$, 
L. harbinensis K.V9.3.1Np was inoculated (1\% inoculum) into fresh MRS broth and incubated for $17 \mathrm{~h}$ at $30^{\circ} \mathrm{C}$ to reach $\sim 2 \times 10^{9} \mathrm{CFU} \mathrm{ml}^{-1}$.

Y. lipolytica UBOCC-A-211004 was obtained from the Université de Bretagne Occidentale culture collection (UBOCC, Plouzané, France) and was stored in yeast extract and malt based medium (YEMA) supplemented with $30 \%(\mathrm{v} / \mathrm{v})$ glycerol at $-80^{\circ} \mathrm{C}$. After cultivation on potato dextrose agar (PDA) for $7 \mathrm{~d}$ at $25^{\circ} \mathrm{C}$, several colonies were suspended in potato dextrose broth (PDB) followed by incubation for $20 \mathrm{~h}$ at $25^{\circ} \mathrm{C}$ under shaking at $120 \mathrm{rpm}$.

\subsection{Fermented milk preparation and cell-free supernatant recovery}

Fermented milks supplemented or not with the bioprotective strain were prepared as previously described (Delavenne et al. 2013). Briefly, $500 \mathrm{ml}$ of half-fat pasteurized milk were mixed with milk powder $(4 \%)$, heated at $85^{\circ} \mathrm{C}$ for $30 \mathrm{~min}$ and cooled to $45^{\circ} \mathrm{C}$ before being inoculated with a commercial yogurt starter culture containing Streptococcus salivarius subsp. thermophilus (S. thermophilus) and Lactobacillus delbrueckii subsp. bulgaricus ( $L$. bulgaricus) ('ferments lyophilisés pour yaourt brassé', Nat-Ali, Nantes, France) following the manufacturer's instructions. Then, $30 \mathrm{ml}$ of inoculated milk were distributed into $100-\mathrm{ml}$ sterile containers prior to fermentation. In order to prepare fermented milks supplemented with the bioprotective strain, L. harbinensis K.V9.3.1Np cells obtained from MRS broth were centrifuged twice for $10 \mathrm{~min}$ at $10000 \mathrm{~g}$ and washed with sterile peptone water, before being suspended and diluted in $30 \mathrm{ml}$ of half-fat pasteurized milk to reach a concentration of $10^{9}$ CFU $\mathrm{ml}^{-1}$. This suspension $(1.5 \mathrm{ml})$ was then inoculated to reach a final concentration of $5 \times 10^{7} \mathrm{CFU} \mathrm{m}{ }^{-1}$ into $30 \mathrm{ml}$ of milk already containing the commercial yogurt starter culture as described above.

Fermentations were conducted at $42^{\circ} \mathrm{C}$ for $6 \mathrm{~h}$ and $\mathrm{pH}$ was recorded before and after fermentation using a surface $\mathrm{pH}$ meter (Eutech instruments, Cyberscan $\mathrm{pH} 510$ ). After storage 
for 2 weeks at $10^{\circ} \mathrm{C}$, the $\mathrm{pH}$ of the control and active supernatants was recorded and $L$. bulgaricus, S. thermophilus and L. harbinensis K.V9.3.1Np were enumerated on acidified MRS agar (pH 5.5) at $37^{\circ} \mathrm{C}$ (Randazzo et al., 2002), M17 supplemented with $0.5 \%$ lactose at $30^{\circ} \mathrm{C}$ (Ashraf and Shah, 2011) and LAMVAB (Hartemink et al., 1997) at 30 ${ }^{\circ} \mathrm{C}$, respectively. Fermented milks were centrifuged for $10 \mathrm{~min}$ at $17500 \mathrm{~g}$ and the supernatants were filtersterilized using a $0.22 \mu \mathrm{m}$ cellulose acetate membrane filter (Sartorius Stedim Biotech, France) prior to storage at $-80^{\circ} \mathrm{C}$. Two distinct batches of approximately $160-190 \mathrm{ml}$ of both active and control supernatants were prepared.

\subsection{Effect of fermented milk supernatant on Y. lipolytica growth and physiology}

Y. lipolytica cells were harvested from PDB broth at the end of exponential growth phase after centrifugation for $15 \mathrm{~min}$ at $420 \mathrm{~g}$ and suspended in physiological saline solution (PSS). Cells were then inoculated at $10^{6}$ cells $\mathrm{ml}^{-1}$ for flow cytometry and $10^{7}$ cells $\mathrm{ml}^{-1}$ for SEM analyses, either in supernatant obtained without (control supernatant) or with L. harbinensis K.V9.3.1 Np (active supernatant) as well as in supernatants supplemented with either $200 \mathrm{mM}$ acetic acid or $20 \mathrm{~g} \mathrm{ml}^{-1}$ natamycin (Sigma-Aldrich, France) (positive controls). Finally, $2 \mathrm{ml}$ of supernatant containing yeast cells were transferred into a 24-well cell plate (Corning Incorporated Costar United States) and incubated up to $10 \mathrm{~d}$ at $10^{\circ} \mathrm{C}$. After 3,6 and $10 \mathrm{~d}, Y$. lipolytica cells were enumerated with a Malassez cell counting chamber (after dilution in PSS if appropriate) and on PDA after incubation for $11 \mathrm{~d}$ at $10^{\circ} \mathrm{C}$. No further growth was observed after this incubation time.

At the end of each incubation period, yeast cells were centrifuged for $15 \mathrm{~min}$ at $420 \mathrm{~g}$ and pellets were re-suspended in PSS and then left on ice prior to flow cytometry analyses. Yeast morphology was also assessed using scanning-electron microscopy (SEM) as described below. 


\subsubsection{Flow cytometry analyses}

Flow cytometry analyses were performed using a BD Accuri C6 flow cytometer and analyzed with the BD Accuri C6 software (Becton Dickinson, New Jersey, USA). The FL-1, FL-2, FL3 and FL-4 channels were collected through a $530 \mathrm{~nm}$, a $585 \mathrm{~nm}$, a >670 nm and a $675 \mathrm{~nm}$ bandpass filters, respectively. Compensation for spectral overlap between channels was performed using unlabeled and single stained cell populations. A total of 10000 cells were analyzed for each assay. In addition, two biologically independent experiments were performed for each analysis.

\subsubsection{Cell viability assessment}

To assess $Y$. lipolytica cell viability after incubation in active and control supernatants, the LIVE/DEAD BacLight viability kit (Molecular Probes, France) was used according to the manufacturer's instructions. In this kit, SYTO 9 stains all cells, whereas propidium iodide (PI) only enters cells with damaged cytoplasmic membranes. Briefly, $0.25 \mu$ l of SYTO 9 (3.34 $\left.\mathrm{mM} ; \lambda_{\mathrm{ex}} / \lambda_{\mathrm{em}}: 480 / 500 \mathrm{~nm}\right)$ and PI $\left(20 \mathrm{mM} ; \lambda_{\mathrm{ex}} / \lambda_{\mathrm{em}}: 490 / 635 \mathrm{~nm}\right)$ were added to $250 \mu \mathrm{l}$ of yeast cells in PSS. Samples were then incubated for $20 \mathrm{~min}$ in darkness at room temperature, before direct analysis by flow cytometry. SYTO 9 and PI fluorescence was measured using the FL1 and FL2 channels, respectively.

Untreated and heat-treated cells were used as controls to validate the staining method. For both untreated and heat-treated controls, $1 \mathrm{ml}$ of $Y$. lipolytica cells from a fresh PDB culture (end of exponential growth phase) was centrifuged for $15 \mathrm{~min}$ at $420 \mathrm{~g}$, the pellet resuspended in $1 \mathrm{ml}$ of PSS and the cell density adjusted to $5 \times 10^{6}$ cells $\mathrm{ml}^{-1}$. For heat-treatment, cells were placed for $10 \mathrm{~min}$ in an $80^{\circ} \mathrm{C}$ water bath. For the untreated and heat-treated cells, 3 samples of $250 \mu 1$ were stained prior to flow cytometry analysis. The first sample was stained with 0.25 
$\mu 1$ of SYTO 9, the second sample was stained with $0.25 \mu \mathrm{l}$ of PI and the last sample was stained with a mixture of these two dyes as described above.

\subsubsection{Cell membrane potential assessment}

To assess the cell membrane potential of $Y$. lipolytica, a mixture of 3,3'dihexyloxacarbocyanine iodide $\left(\mathrm{DIOC}_{6}(3) ; \lambda_{\mathrm{ex}} / \lambda_{\mathrm{em}}: 484 / 501 \mathrm{~nm}\right)$ (Molecular probes, France) and PI dyes was used (Freitas et al., 2012). $\mathrm{DIOC}_{6}(3)$ is a carbocyanine derivative with short alkyl tails that accumulates in polarized and hyperpolarized cytoplasmic and mitochondrial membranes, due to its positive charge. PI was used as described above while $\operatorname{DIOC}_{6}(3)$ was prepared following the manufacturer's instructions. Prior to staining, a $10 \mu \mathrm{M} \mathrm{DIOC}{ }_{6}(3)$ working solution was prepared from a $1 \mathrm{mM} \mathrm{DIOC}_{6}(3)$ stock solution in DMSO kept at $80^{\circ} \mathrm{C}$. $\mathrm{DIOC}_{6}(3)(1.25 \mu \mathrm{l})$ and $\mathrm{PI}(0.25 \mu \mathrm{l})$ were added to $250 \mu \mathrm{l}$ of yeast cell suspension in PSS. Samples were incubated for $15 \mathrm{~min}$ at $37^{\circ} \mathrm{C}$ in darkness, cells were then centrifuged for $15 \mathrm{~min}$ at $420 \mathrm{~g}$ and resuspended in $250 \mu \mathrm{l}$ of PSS before flow cytometry analysis. $\mathrm{DIOC}_{6}(3)$ and PI fluorescence were measured using the FL1 and FL2 channel, respectively.

Untreated and heat-treated cells were used as controls to validate the staining method and were prepared as described above. Three samples for each condition were stained prior to flow cytometry analysis. The first sample was stained with $1.25 \mu$ l of $\operatorname{DIOC}_{6}(3)$, the second sample was stained with $0.25 \mu$ l of PI and the last sample was stained with a mixture of these two dyes as described above. Carbonyl cyanide 3-chlorophenylhydrazone (CCCP; SigmaAldrich, France)-treated cells were also used as an additional control. CCCP is a proton ionophore used to quickly collapse the membrane potential. To prepare CCCP-treated control samples, $500 \mu \mathrm{l}$ of a $5 \times 10^{6}$ cells $\mathrm{ml}^{-1}$ suspension were incubated in the presence of $0.5 \mu 1$ of a $15 \mathrm{mg} \mathrm{ml}^{-1} \mathrm{CCCP}$ solution and $2.5 \mu \mathrm{l}$ of a $1 \mathrm{mM} \mathrm{DIOC}_{6}(3)$ solution for $5 \mathrm{~min}$ at $37^{\circ} \mathrm{C}$ in darkness and washed as described above prior to flow cytometry analysis. 


\subsubsection{ROS production assessment}

To perform this analysis, dihydrorodhamine 123 was used as previously described (Freitas et al. 2012). Dihydrorodhamine 123 is a non-fluorescent ROS indicator than can passively diffuse across membranes and can be oxidized to cationic rodhamine 123 , which exhibits a green fluorescence informing on the degree of ROS accumulation in cells. A working solution at $330 \mathrm{mg} \mathrm{ml}^{-1}$ dihydrorodhamine 123 (Invitrogen, France) was prepared in DMSO and stored at $-80^{\circ} \mathrm{C}$. Ten microliters of this solution were added to $250 \mu 1$ of yeast cell suspension. Samples were then incubated for $10 \mathrm{~min}$ in darkness at room temperature followed by centrifugation for $15 \mathrm{~min}$ at $420 \mathrm{~g}$ and resuspension of the pellet in $250 \mu \mathrm{l}$ PSS before analysis. Rodhamine 123 fluorescence was measured using the FL1 channel.

To validate the staining method, untreated (fresh) cells and cells incubated in the presence of $3 \% \mathrm{H}_{2} \mathrm{O}_{2}$ for 40 min were used as controls.

\subsubsection{Intracellular $\mathrm{pH}(\mathrm{pHi})$ assessment}

The carboxy SNARF-4F AM (SNARF-4F 5-(and-6)-carboxylic acid, acetoxymethyl ester acetate) (Molecular probes, France) $\mathrm{pH}$-dependent fluorescent probe, was used to assess pHi. This probe is a fluorinated derivative of carboxy SNARF-1 and is well adapted for pHi determination in yeast cells. It is a ratiometric $\mathrm{pH}$ indicator as it displays two inversely related pH-dependent emission spectra at two different wavelengths (Boyer and Hedley, 1994; Santos and Maquina, 2004; Valli et al., 2005). A calibration curve for pHi determination of $Y$. lipolytica cells was obtained using a method previously described by Valli et al. (2005), with slight modifications.

For each experiment, a calibration curve was built in order to link the fluorescence ratio to the corresponding cell pHi. For each of the 7 measurements performed to build the curve, $1 \mathrm{ml}$ of 
fresh $Y$. lipolytica cells $\left(5 \times 10^{6}\right.$ cells $\left.\mathrm{ml}^{-1}\right)$ was washed by centrifugation for $15 \mathrm{~min}$ at $420 \mathrm{~g}$, and resuspended in $250 \mu \mathrm{l}$ of loading buffer (McIlvaine buffer at $\mathrm{pH} 5.5$ with a $20 \mu \mathrm{M}$ carboxy SNARF-4F AM final concentration). Cells were incubated for $11 \mathrm{~min}$ in darkness at $28^{\circ} \mathrm{C}$ under agitation, using an orbital shaker at $150 \mathrm{rpm}$ allowing the probe to penetrate the cells. Cells were then washed and resuspended in $250 \mu 1$ of different McIlvaine buffers (pH ranging from 4 to 8) supplemented with $30 \mu \mathrm{M}$ of amphotericin B (Sigma Aldrich, France) as described by Valli et al. (2005). Cells were incubated for $1 \mathrm{~h}$ at $37^{\circ} \mathrm{C}$ in darkness under agitation $(150 \mathrm{rpm})$ and kept on ice prior to flow cytometry analysis. The two $\mathrm{pH}$-dependent emission spectra were recorded using the FL2 and FL4 channels. The calibration curve was then obtained by plotting the fluorescence ratio (FL2/FL4) of each sample with respect to the $\mathrm{pH}$ of the different Mcllvaine buffers using a second-order polynomial function. To determine yeast cell pHi from the different assays, the cell suspension was centrifuged for $5 \mathrm{~min}$ at 11 $000 \mathrm{~g}$, and the supernatant was kept at room temperature until further use. The pellet was suspended in $250 \mu 1$ loading buffer and incubated as described above. After a washing step, the supernatant was discarded and the pellet resuspended in $250 \mu$ l of its respective supernatant and incubated for an additional $2.5 \mathrm{~h}$ in darkness at room temperature before flow cytometry analysis. pHi was also determined for fresh cells $\left(5 \times 10^{6}\right.$ cells $\left.\mathrm{ml}^{-1}\right)$ following the same protocol. The obtained fluorescence ratio was converted into pHi value using the equation generated by the calibration curve.

\subsubsection{Scanning electron microscopy (SEM)}

Yeast cell morphology after 3 and $6 \mathrm{~d}$ incubation in the control and active supernatants was investigated using conventional SEM (HITACHI S-3200N). After incubation, $5 \times 10^{6}$ yeast cells (after sample dilution when appropriate) were centrifuged for $7 \mathrm{~min}$ at $6700 \mathrm{~g}$, washed twice in $0.1 \mathrm{M}$ sodium cacodylate buffer at pH 5 (Electron Microscopy Sciences, France) and 
resuspended in $1 \mathrm{ml}$ in the same buffer. After filtration through a $0.22 \mu \mathrm{m}$ polycarbonate membrane filter (Fisher scientific, France), the latter was incubated for $4 \mathrm{~h}$ in a closed Petri dish containing 10 drops of Karnovsky solution, which consisted of $4 \%$ paraformaldehyde and $2.5 \%$ glutaraldehyde in $0.1 \mathrm{M}$ cacodylate buffer ( $\mathrm{pH}$ 5). Finally, the filter was removed from the Petri dish and left to air-dry overnight in a new Petri dish before SEM analysis.

\subsection{Organic acid quantification in fermented milk supernatants}

Organic acids present in control and active supernatants were quantified as previously described (Belguesmia et al. 2014) with a high-performance liquid chromatograph (HPLC) Agilent 1100 series (Agilent Technologies, Santa Clara, CA) equipped with a Rezex ROAOrganic Acid analysis column (300 x $7.8 \mathrm{~mm}$, Phenomenex, Australia), a UV detector set at $210 \mathrm{~nm}$ and a refractive index detector. External standard curves of succinic, lactic, acetic, 2pyrrolidone-5-carboxylic, L-3-phenyllactic, hexanoic, hydroxyphenyllactic, 2hydroxybenzoic and salicylic acids (Sigma, St Louis, MO) were used for quantification.

\subsection{Statistical analyses}

Statistical analyses were performed using Statistica for Windows (version 10 Statsoft Inc., Tulsa, USA). Analysis of variance (ANOVA) and a Fisher's least significant difference test $(P<0.05)$ were applied on data obtained from bacterial enumerations and flow cytometry analyses to detect any significant differences between treatments for each incubation period or between each incubation period for each treatment. A student t-test was applied to concentrations of organic acids obtained by HPLC to detect any significant differences between control and active supernatants $(P<0.05)$.

\section{Results}




\section{1. $p H$ and bacterial enumeration}

After storage for 2 weeks, the $\mathrm{pH}$ of control yogurt $(\mathrm{pH} 4.2 \pm 0.1)$ and fermented milk supplemented with L. harbinensis K.V9.3.1.Np ( $\mathrm{pH} 4.3 \pm 0.1)$ were similar $(P>0.05)$. Starter culture concentrations were similar in both fermented milks with $7.8 \pm 0.2 \log _{10} \mathrm{CFU} \mathrm{ml}{ }^{-1}$ and 9.0 $\pm 0.1 \log _{10} \mathrm{CFU} \mathrm{ml} \mathrm{m}^{-1}$ for L. bulgaricus and S. thermophilus, respectively. L. harbinensis K.V9.3.1.Np population was estimated at $8.0 \pm 0.2 \log _{10} \mathrm{CFU} \mathrm{m}{ }^{-1}$. These results were consistent with those of Delavenne et al. (2013), showing that the bioprotective strain did not interfere with acidification properties and starter culture growth.

\subsection{Effects of fermented milk supernatants on Y. lipolytica cell population and viability}

Y. lipolytica cell population and viability in the different supernatants were monitored over time (3, 6 and 10 d) using a Malassez cell counting chamber, surface-plating on PDA as well as flow cytometry.

As shown in Figure 1A, Y. lipolytica grew within $3 \mathrm{~d}$ in the control supernatant and reached cultivable populations of $7.4 \pm 0.4 \log _{10} \mathrm{CFU} \mathrm{ml}{ }^{-1}$ after $6 \mathrm{~d}$. Yeast populations estimated using a Malassez cell counting chamber were higher with counts $0.5 \log _{10}$ to $1.8 \log _{10}$ above cultivable populations. In contrast, cultivable yeast populations determined on PDA significantly decreased after $3 \mathrm{~d}$ incubation in the active supernatant and supernatants supplemented with acetic acid or natamycin $(P<0.05)$. It is worth mentioning that colony formation of yeasts obtained from active supernatant was markedly slower than that of yeasts from control supernatant (Figure S1), suggesting that active supernatant stressed the yeast cells. Finally, while cultivable population remained stable after 6 and $10 \mathrm{~d}$ in the supernatants supplemented with acetic acid or natamycin, yeast cell counts in active supernatant slightly increased from $4.3 \log _{10} \mathrm{CFU} \mathrm{ml}{ }^{-1}$ on $\mathrm{d} 3$ to $5.6 \mathrm{CFU} \mathrm{ml}^{-1}$ on $\mathrm{d} 10$. Cell counts per millilitre determined with a Malassez cell counting chamber remained stable over time $\left(\sim 6 \log _{10}\right.$ cells 
$\mathrm{ml}^{-1}$ ) in active and supernatants supplemented with acetic acid or natamycin, while it increased up to $\sim 8 \log _{10}$ cells $\mathrm{ml}^{-1}$ in the control supernatant (Figure $1 \mathrm{~A}$ ).

Cell proportions presenting undamaged or damaged membranes were estimated using the LIVE/DEAD BacLight viability kit combined with flow cytometry. First, fresh and heattreated Y. lipolytica cells were stained with both SYTO 9 and PI dyes. As expected, fresh cell staining leaded to $99.7 \%$ of viable cells (with undamaged membrane), whereas $99.9 \%$ of permeabilized cells were obtained for heat-treated cells (Figure S2). Except in the supernatant supplemented with natamycin, no significant difference in the high proportion of cells with undamaged membranes was obtained $(P>0.05)$, indicating that these treatments did not affect membrane permeability, whatever the incubation period. Indeed, the mean percentage of cells with undamaged membrane respectively ranged from $86.7 \pm 2.0$ to $99.1 \pm 0.6 \%, 86.6 \pm 11.4$ to $90.9 \pm 1.5 \%$ and from $82.8 \pm 11.1$ to $95.3 \pm 1.3 \%$, after incubation respectively in the control supernatant, in the supernatant supplemented with acetic acid and in the active supernatant (Figure 1B). In contrast, the cell proportion presenting undamaged membrane dramatically decreased in the supernatant supplemented with natamycin. Indeed, in this condition, cells with undamaged membranes represented $62.6 \pm 2.3 \%$ of the total cells after $3 \mathrm{~d}$, while they only represented $33.3 \pm 21$ and $0.4 \pm 0.3 \%$ of the total cells on $\mathrm{d} 6$ and $\mathrm{d} 10$, respectively (Figure 1B).

\subsection{Effects of fermented milk supernatants on Y. lipolytica cell membrane potential}

Several control experiments were performed to ensure the validity of the method. Fresh $Y$. lipolytica cells were stained with $\mathrm{DIOC}_{6}(3)$ yielding to $90.9 \%$ of cells with polarized cytoplasmic and mitochondrial membranes, while CCCP-treated cells stained with $\mathrm{DIOC}_{6}(3)$ only exhibited $16.4 \%$ of cells with polarized membranes (Figure S3A, S3B). Consequently, the use of this dye for characterization of $Y$. lipolytica membrane potential changes was 
validated. $\mathrm{DIOC}_{6}(3)$ was also combined with PI to stain fresh and heat-treated $Y$. lipolytica cells. As expected, up to $93.6 \%$ of fresh cells had polarized membranes and only $1.5 \%$ had a permeabilized membrane, while all heat-treated cells $(99.8 \%)$ presented a permeabilized membrane (Figure S3C, S3D).

Membrane potential and cell integrity were evaluated for all treatments after incubation for 3, 6 and $10 \mathrm{~d}$ (Table 1). Despite a significant decrease of mean percentages of intact and polarized membrane cells observed between d 3 and d 6 for both the control and the active supernatants $(P<0.05)$, the mean percentages were significantly lower in active than in the control supernatant $(P<0.05)$. This membrane polarity loss was concomitant with a significant increase in depolarized membrane $(P<0.05)$ but not with permeabilized membrane cells $(P>0.05)$, as previously observed after SYTO 9/PI staining. Nevertheless, between $\mathrm{d} 6$ and $\mathrm{d}$ 10, the mean polarized membrane cell percentage significantly increased in the active supernatant to reach a similar mean percentage as in the control supernatant $(P<0.05)$. Interestingly, a similar trend to that observed in active supernatant was obtained for the supernatant supplemented with acetic acid.

In contrast, cells incubated with natamycin behaved differently. Indeed, after $3 \mathrm{~d}$, a high proportion of permeabilized membrane cells was observed. After $6 \mathrm{~d}$, more than $50 \%$ of total cells exhibited a depolarized membrane, which was again accompanied by an important increase in the proportion of permeabilized membrane cells at d 10 (Table 1).

\subsection{Effects of fermented milk supernatants on ROS production in Y. lipolytica}

$\mathrm{H}_{2} \mathrm{O}_{2}$ treatment of $Y$. lipolytica cells, followed by dihydrorodhamine 123 staining, oxidized most cells (99.1\%) as compared to untreated fresh cells (5.3\%), validating the use of this dye for monitoring ROS production in $Y$. lipolytica (Figure S4). As shown in Figure 2, ROS production was detected for all tested conditions. Overall, higher proportions of ROS- 
producing cells were observed in supernatant supplemented with acetic acid and natamycin than in the control and active supernatants; however this trend was not statistically significant $(P>0.05)$ (Figure 2).

\subsection{Effects of fermented milk supernatants on Y. lipolytica intracellular pH}

A calibration curve was first generated by plotting the fluorescence ratios $(580 \mathrm{~nm} / 640 \mathrm{~nm})$ of the carboxy SNARF-4F AM probe against their corresponding $\mathrm{pH}$ equilibrated cell values. A second degree polynomial model was fitted to the experimental data (Figure S5) and used for the pHi calculations in the tested conditions. Based on the appearance of the calibration curve, pHi calculations were less accurate when $\mathrm{pHi}$ were higher than 6.5. Intracellular $\mathrm{pH}$ of fresh cells harvested at the end of the exponential phase and grown in PDB was $6.5 \pm 0.2$.

As shown in Table 2, after $3 \mathrm{~d}$ incubation, $Y$. lipolytica $\mathrm{pHi}$ was approximately $1 \mathrm{pH}$ unit lower in active (pHi ranging from 3.81 to 4.18 ) than in the control supernatant (pHi ranging from 4.94 to 4.99 ) despite that both the active and the control supernatants had similar $\mathrm{pH}$ (4.2 and 4.3, respectively). After $10 \mathrm{~d}$, similar pHi values were obtained with pHi comprised between $\sim 5.4$ and $\sim 5$ for both the active and the control supernatants.

Cells incubated in control supernatant supplemented with acetic acid presented $<3.8 \mathrm{pHi}$ values throughout incubation, while pHi values of cells incubated in supernatant supplemented with natamycin were below 3.8 after $3 \mathrm{~d}$ incubation and then increased to 4.94 and 4.99 on d 6 and d 10, respectively (Table 2).

\subsection{Effect of fermented milk supernatants on Y. lipolytica cell morphology}

Yeast morphology was monitored after 3 and $6 \mathrm{~d}$ incubation in all tested conditions using

SEM (Figure 3). Cells incubated in active supernatant displayed more ultrastructural changes (Figure 3B) than cells in control supernatant (Figure 3A). Indeed, we could observe cells at 
different collapsing state of their cytoplasmic membrane (i.e. cells displaying a hole, which was presumably broadening with time) as well as lysed cells characterized by the sole presence of their cytoplasmic membrane. Similar observations were made for cells incubated in the supernatant supplemented with acetic acid (Figure 3C) and the one with natamycin (Figure 3D).

\subsection{Organic acids quantification}

Nine organic acids with known antifungal activities were searched for and quantified in the control and active supernatants using HPLC. In the control supernatant, three organic acids (ie. hexanoic, benzoic and salicylic acids) were not found while in the active supernatant, all organic acids were detected and quantified, except salicylic acid (Table 3). Concentrations of the two organic acids, only quantified in the active supernatant, were $1.03 \mathrm{mM}$ for the hexanoic acid and $0.19 \mathrm{mM}$ for the 2-hydroxybenzoic acid. Except for succinic acid, the detected acids were present at significantly higher concentrations in the active supernatant than in the control supernatant. This was particularly remarkable for lactic, acetic and 2pyrrolidone-5-carboxylic acids, which concentrations were 1.5- (for lactic acid) to 30-fold (for acetic acid) higher in the active supernatant than in the control one.

\section{Discussion}

During the last decade, numerous publications have described the antifungal activity of selected LAB strains against a large diversity of spoilage fungi occurring in various foods and feed (for a review see Dalié et al. 2010 and Crowley et al. 2013). As underlined by Crowley et al. (2013), while there is an increased knowledge on the nature of the produced antifungal compounds, little information is available regarding the impact of these metabolites on the target fungal species. In the present study, we investigated how the metabolites produced by 
L. harbinensis K.V9.3.1Np affected the physiological status and cell morphology of $Y$. lipolytica, an acid resistant yeast commonly involved in spoilage of dairy products. These effects were also compared with those of two well-known antifungal compounds, namely acetic acid and natamycin, which exhibit different action modes.

The first striking effect of the cell-free supernatant obtained from fermented milk made with L. harbinensis K.V9.3.1Np was its fungistatic activity for up to $10 \mathrm{~d}$ against $Y$. lipolytica, a yeast considered to be difficult to inhibit (Prahailong and Fleet, 1997). Using LIVE/DEAD staining combined with flow cytometry analysis, we showed that yeast cells were still viable indicating that the metabolites present in the active supernatant had a fungistatic rather than fungicidal effect. This result was confirmed by a significant cultivability loss and a subsequent delayed detection of yeast colonies on agar plates. Indeed, cultivable cells decreased of up to $2 \log _{10} \mathrm{CFU} \mathrm{ml} \mathrm{m}^{-1}$ after incubation in active supernatant while at the same time, yeast cell numbers remained stable and $\sim 90 \%$ of cells had an undamaged membrane. Thus, it indicates that a very large proportion of cells were under a viable but not cultivable (VNC) state. The VNC state, in which cells maintain a detectable metabolic activity but are unable to grow on culture media, has been extensively studied in pathogenic bacteria but also exists in yeast (Hawser and Islam, 1999; Salma et al., 2013; Yamamoto, 2000). Furthermore, the present results were in agreement with those of Delavenne et al. (2015), showing the remarkable antifungal activity of $L$. harbinensis K.V9.3.1Np in fermented milk. Moreover, it is worth mentioning that the $Y$. lipolytica inoculum level used in this study $\left(10^{6} \mathrm{CFU} \mathrm{ml}{ }^{-1}\right.$ of supernatant) does not reflect the yeast population usually encountered during spoilage, which is generally far lower $\left(<100 \mathrm{CFU} \mathrm{g}^{-1}\right)$. Thus, the obtained results can be associated with a worst-case scenario and suggest even stronger results in the presence of low population contamination. 
No significant effect on yeast cell membrane permeability and ROS production were observed for the active supernatant, while this supernatant induced cell membrane depolarization and pHi decrease, both likely responsible for growth inhibition and yeast cell cultivability loss. Interestingly, the effect of fermented milk supernatant supplemented with acetic acid was quite similar to that observed with the active supernatant. Organic acids quantification showed that known antifungal organic acids were significantly more abundant in the active supernatant than in the control one. Among them, lactic and acetic acids were found in large quantities (235.86 and $11.57 \mathrm{mM}$, respectively) while 2-pyrrolidone-5-carboxylic, hexanoic and 2-hydroxybenzoic acids were found in much lower concentrations (from 0.19 to 1.03 $\mathrm{mM}$ ). These results and the observed physiological changes supported the idea that the antifungal activity of L. harbinensis K.V9.3.1Np may be due to the synergistic action of organic acids as also shown by other authors (Belguesmia et al. 2014; Dalié et al. 2010). Indeed, at low extracellular $\mathrm{pH}$, weak acids are able to diffuse through the cytoplasmic membrane and enter the cell. The neutral pHi causes their dissociation into charged anions, which are not able to diffuse back out causing intracellular acidification (Stratford et al., 2013; Ullah et al., 2012). Furthermore, an indirect consequence of a weak acid stress could be the disturbance of the cytoplasmic membrane (Krebs et al., 1983; Neal et al., 1965; Sikkema et al., 1995; Stratford and Anslow, 1998). It would be interesting to further investigate the contribution of these organic acids to the antifungal activity by determining their minimum inhibitory concentrations (MICs) both individually and in mixture and their mode of action. Similar severe physiological changes were observed on the wine-related yeast Hanseniaspora guilliermondii in response to antimicrobial peptides (AMPs) produced by Saccharomyces cerevisiae (Branco et al. 2015). After 24h of exposure, AMPs permeabilized the membrane of most yeast cells disturbing pHi homeostasis and leading to a total cultivability loss. 
In the present study, physiological changes of yeast cells when cells were incubated with active supernatant were also accompanied by ultrastructural changes as shown by conventional SEM. Indeed, after 6 d incubation, cells with irregular shapes at different stages of collapsing of their cytoplasmic membrane were observed while after incubation in control supernatant cells were intact with a smooth surface. The different stages of collapsing were characterised by cells displaying a hole, which is presumably broadening with time as well as lysed cells (cells with the sole presence of their cytoplasmic membrane). However, these effects were not as severe as those observed for natamycin, which directly targets ergosterol in the cytoplasmic membrane (Te Welscher et al., 2008). These observed morphological changes may be the result of an autophagy phenomenon, which is a nutrient degradation and recycling process. Indeed, cell component degradation helps to prolong cell survival or allows differentiation during specific conditions such as nutrient starvation (e.g., carbon, nitrogen), physical stress, growth factor limitation and ROS accumulation caused by oxidative stress (Khan et al., 2012; Lichtenstein et al., 2010; Mizushima and Klionsky, 2007). This phenomenon can ultimately lead to cellular degradation, apoptosis and cell death (Khan et al., 2012). It can be hypothesized that organic acids present in the active supernatant are also responsible for the observed morphological changes. Nevertheless, after incubation for $10 \mathrm{~d}$ in the active supernatant, $Y$. lipolytica was able to return to its initial physiological state, thus showing its remarkable adaptation capacity and high resistance towards organic acids as previously shown (Praphailong and Fleet, 1997).

In conclusion, the present study has brought new information on the antifungal mechanism of a bacterial bioprotective culture able to prevent fungal spoilage in fermented milk. Indeed, despite the viability of the yeast cells, L. harbinensis K.V9.3.1Np metabolites, in particular organic acids such as acetic, lactic, 2-pyrrolidone-5-carboxylic, hexanoic and 2hydroxybenzoic acids, may act in a synergetic manner to prevent $Y$. lipolytica growth by 
inducing membrane depolarization and pHi decrease. It was also shown that a sub-population of cells was under a VNC state and that cells could undergo morphological changes such as membrane collapsing and cell lysis. It would be of interest to investigate the response of $Y$. lipolytica at the gene and protein expression levels to identify which cellular functions are targeted and how $Y$. lipolytica is able to cope with the stress generated by L. harbinensis K.V9.3.1Np metabolites.

\section{Acknowledgements}

The authors thank G. Sinquin (Université de Bretagne Occidentale, Plateforme d'imagerie et de mesures en microscopie) for his technical assistance in SEM imaging.

\section{References}

Ashraf, R., Shah, N. P., 2011. Selective and differential enumerations of Lactobacillus delbrueckii subsp. bulgaricus, Streptococcus thermophilus, Lactobacillus acidophilus, Lactobacillus casei and Bifidobacterium spp. in yoghurt-A review. International journal of food microbiology 149, 194-208.

Aunsbjerg, S. D., Honoré, A. H., Marcussen, J., Ebrahimi, P., Vogensen, F. K., Benfeldt, C., Skov, T., Knøchel, S., 2015. Contribution of volatiles to the antifungal effect of Lactobacillus paracasei in defined medium and yogurt. International journal of food microbiology 194, 46-53.

Belguesmia, Y., Rabesona, H., Mounier, J., Pawtowsky, A., Le Blay, G., Barbier, G., Haertlé, T., Chobert, J. M., 2014. Characterization of antifungal organic acids produced by Lactobacillus harbinensis K. V9. 3.1 Np immobilized in gellan-xanthan beads during batch fermentation. Food Control 36, 205-211.

Bernardeau, M., Vernoux, J. P., Henri-Dubernet, S., Guéguen, M., 2008. Safety assessment of 
dairy microorganisms: the Lactobacillus genus. International Journal of Food Microbiology 126, 278-285.

Boyer, M. J., D. W. Hedley., 1994. Measurement of intracellular pH. Methods in Cell Biology $41,135-148$.

Branco, P., Viana, T., Albergaria, H., Arneborg, N., 2015. Antimicrobial peptides (AMPs) produced by Saccharomyces cerevisiae induce alterations in the intracellular $\mathrm{pH}$, membrane permeability and culturability of Hanseniaspora guilliermondii cells. International journal of food microbiology 205, 112-118.

Corsetti, A., Gobetti, M., Rossi, J., Damiani, P., 1998. Antimould activity of sourdough lactic acid bacteria: identification of a mixture of organic acids produced by Lactobacillus sanfrancisco CB1. Applied Microbiology and Biotechnology 50, 253-256.

Crowley, S., Mahony, J., van Sinderen, D., 2012. Comparative analysis of two antifungal Lactobacillus plantarum isolates and their application as bioprotectants in refrigerated foods. Journal of Applied Microbiology 113, 1417-1427.

Crowley, S., Mahony, J., van Sinderen, D., 2013. Current perspectives on antifungal lactic acid bacteria as natural bio-preservatives. Trends in Food Science and Technology 33, 93-109.

Dalié, D. K. D., Deschamps, A. M., Richard-Forget, F., 2010. Lactic acid bacteria - potential for control of mould growth and mycotoxins: a review. Food Control 21, 370-380.

Davidson, M. P., 2001. Chemical preservatives and natural antimicrobial compounds. In M. P. Doyle, L. R. Beuchat, \& T. J. Montville (Eds.), Food microbiology: Fundamentals and frontiers, Washington: ASM press, pp. 593-627.

Delavenne, E., Cliquet, S., Trunet, C., Barbier, G., Mounier, J., Le Blay, G., 2015. Characterization of the antifungal activity of Lactobacillus harbinensis K. V9. $3.1 \mathrm{~Np}$ and Lactobacillus rhamnosus K. C8. 3.1 I in yogurt. Food microbiology 45, 10-17. 
Delavenne, E., Ismail, R., Pawtowski, A., Mounier, J., Barbier, G., Le Blay, G., 2013. Assessment of lactobacilli strains as yogurt bioprotective cultures. Food Control 30, 206-213.

Delavenne, E., Mounier, J., Asmani, K., Jany, J. L., Barbier, G., Le Blay, G., 2011. Fungal diversity in cow, goat and ewe milk. International Journal of Food Microbiology 151, 247-251.

Delavenne, E., Mounier, J., Déniel, F., Barbier, G., Le Blay, G., 2012. Biodiversity of antifungal lactic acid bacteria isolated from raw milk samples from cow, ewe and goat over one-year period. International Journal of Food Microbiology 155, 185-190.

Fleet, G., 1990. Yeasts in dairy products. Journal of Applied Microbiology 68, 199-211.

Freitas, C., Neves, E., Reis, A., Passarinho, P. C., Da Silva, T. L., 2012. Effect of Acetic Acid on Saccharomyces carlsbergensis ATCC 6269 Batch Ethanol Production Monitored by Flow Cytometry. Applied biochemistry and biotechnology 168, 1501-1515.

Hartemink, R., Domenech, V., Rombouts, F., 1997. LAMVAB - a new selective medium for the isolation of lactobacilli from faeces. Journal of Microbiological Methods 29, 77-84.

Hawser, S., Islam, K. 1999. Comparisons of the effects of fungicidal and fungistatic antifungal agents on the morphogenetic transformation of Candida albicans. Journal of Antimicrobial Chemotherapy, 43, 411-413.

Hymery, N., Vasseur, V., Coton, M., Mounier, J., Jany, J. L., Barbier, G., Coton, E., 2014. Filamentous fungi and mycotoxins in cheese: a review. Comprehensive Reviews in Food Science and Food Safety 13, 437-456.

Khan, I. A., Lu, J. P., Liu, X. H., Rehman, A., Lin, F. C., 2012. Multifunction of autophagyrelated genes in filamentous fungi. Microbiological research 167, 339-345.

Krebs, H.A., Wiggins, D., Stubs, M., Sols, A. Bedoya, F., 1983. Studies on the mechanism of the antifungal action of benzoate. Biochemical Journal 214, 657-663. 
Langa, S., Landete, J. M., Martín-Cabrejas, I., Rodríguez, E., Arqués, J. L., Medina, M., 2013. In situ reuterin production by Lactobacillus reuteri in dairy products. Food Control 33, 200-206.

Li, H., Liu, L., Zhang, S., Uluko, H., Cui, W., Lv, j., 2013. Potential use of Lactobacillus casei AST18 as a bioprotective culture in yogurt. Food Control 34, 675-680.

Lichtenstein, A., Minogue, P. J., Beyer, E. C., Berthoud, V. M., 2011. Autophagy: a pathway that contributes to connexin degradation. Journal of cell science 124, 910-920.

Mayoral, M. B., Martín, R., Sanz, A., Hernández, P. E., González, I., García, T., 2005. Detection of Kluyveromyces marxianus and other spoilage yeasts in yoghurt using a PCR-culture technique. International Journal of Food Microbiology 105, 27-34.

Mizushima, N., Klionsky, D. J., 2007. Protein turnover via autophagy: implications for metabolism. Annual Review of Nutrition 27, 19-40.

Neal, A. L., Weinstock, J. O., Lampen, J. O., 1965. Mechanisms of fatty acid toxicity for yeast. Journal of bacteriology 90,126-131.

Pawlowska, A. M., Zannini, E., Coffey, A., Arendt, E. K. 2012. Green preservatives": combating fungi in the food and feed industry by applying antifungal lactic acid bacteria. Advances in Food and Nutrition Research, 66, 217-238.

Pitt, J. I., Hocking, A. D., 2009. Fungi and food spoilage. Vol. 519. New York: Springer.

Praphailong, W., Fleet, G. H., 1997. The effect of pH, sodium chloride, sucrose, sorbate and benzoate on the growth of food spoilage yeasts. Food Microbiology 14, 459-468.

Randazzo, C. L., Torriani, S., Akkermans, A. D., de Vos, W. M., Vaughan, E. E., 2002. Diversity, dynamics, and activity of bacterial communities during production of an artisanal Sicilian cheese as evaluated by $16 \mathrm{~S}$ rRNA analysis. Applied and Environmental Microbiology 68, 1882-1892. 
Salma, M., Rousseaux, S., Sequeira-Le Grand, A., Divol, B., Alexandre, H., 2013. Characterization of the viable but nonculturable (VBNC) state in Saccharomyces cerevisiae. PLoS ONE 8, e77600.

Santos, A., D. Marquina., 2004. Ion channel activity by Pichia membranifaciens killer toxin. Yeast 21, 151-162.

Schnürer, J., Magnusson, J., 2005. Antifungal lactic acid bacteria as biopreservatives. Trends in Food Science and Technology 16, 70-78

Sikkema, J., De Bont, J. A., Poolman, B., 1995. Mechanisms of membrane toxicity of hydrocarbons. Microbiological reviews 59, 201-222.

Stratford, M., Anslow, P. A., 1998. Evidence that sorbic acid does not inhibit yeast as a classic 'weak acid preservative'. Letters in Applied Microbiology 27, 203-206.

Stratford, M., Nebe-von-Caron, G., Steels, H., Novodvorska, M., Ueckert, J., Archer, D. B., 2013. Weak-acid preservatives: $\mathrm{pH}$ and proton movements in the yeast Saccharomyces cerevisiae. International journal of food microbiology 161, 164-171.

Te Welscher, Y. M., Hendrik, H., Balagué, M. M., Souza, C. M., Riezman, H., De Kruijff, B., Breukink, E. 2008. Natamycin blocks fungal growth by binding specifically to ergosterol without permeabilizing the membrane. Journal of Biological Chemistry, 283, 6393-6401.

Tropcheva, R., Nikolova, D., Evstatieva, Y., Danova, S., 2014. Antifungal activity and identification of Lactobacilli, isolated from traditional dairy product "katak". Anaerobe $28,78-84$.

Ullah, A., Orij, R., Brul, S., \& Smits, G. J., 2012. Quantitative analysis of the modes of growth inhibition by weak organic acids in Saccharomyces cerevisiae. Applied and environmental microbiology 78, 8377-8387. 
Valli, M., Sauer, M., Branduardi, P., Borth, N., Porro, D., Mattanovich, D., 2005. Intracellular $\mathrm{pH}$ distribution in Saccharomyces cerevisiae cell populations, analyzed by flow cytometry. Applied and environmental microbiology 71, 1515-1521.

Yamamoto, H., 2000. Viable but nonculturable state as a general phenomenon of nonsporeforming bacteria, and its modeling. Journal of Infection and Chemotherapy 6, 112114. 
Table 1. Mean percentage of $Y$. lipolytica cells with polarized, depolarized and permeabilized membrane after incubation for 3, 6 and $10 \mathrm{~d}$ in control and active yogurt supernatants $(n=3$ for each treatment) and in supernatant supplemented with either $200 \mathrm{mM}$ acetic acid or $20 \mu \mathrm{g}$ $\mathrm{ml}^{-1}$ natamycin ( $n=2$ for each treatment). Cells were stained with $\mathrm{DIOC}_{6}(3)$ and propidium iodide (PI) dyes and analysed by flow cytometry.

\section{Cell proportion $(\%) \pm \mathrm{SD}$ as a function}

Treatments Membrane potential and integrity of incubation time (d)

\begin{tabular}{|c|c|c|c|c|}
\hline & & , & 6 & 10 \\
\hline \multirow[t]{3}{*}{ Control supernatant } & Intact cells with polarized membrane & $84.8 \pm 1.4^{\mathrm{a} *}$ & $62.9 \pm 7.7^{b}$ & $77.5 \pm 3.9^{\mathrm{a}}$ \\
\hline & Intact cells with depolarized membrane & $9.4 \pm 4.1^{\mathrm{a}}$ & $35.3 \pm 9^{b}$ & $16.9 \pm 11.8^{\mathrm{a}}$ \\
\hline & Cells with permeabilized membrane & $5.2 \pm 4.7^{\mathrm{a}}$ & $1.8 \pm 1.3^{\mathrm{a}}$ & $5.6 \pm 8.7^{\mathrm{a}}$ \\
\hline \multirow[t]{3}{*}{ Active supernatant } & Intact cells with polarized membrane & $68.6 \pm 9.4^{\mathrm{a}}$ & $14.1 \pm 16^{b}$ & $78.9 \pm 4.4^{\mathrm{a}}$ \\
\hline & Intact cells with depolarized membrane & $22.8 \pm 6.8^{\mathrm{a}}$ & $82.1 \pm 19.1^{\mathrm{b}}$ & $10.9 \pm 4.5^{\mathrm{a}}$ \\
\hline & Cells with permeabilized membrane & $7.4 \pm 2.1^{\mathrm{a}}$ & $3.7 \pm 2.9^{\mathrm{a}}$ & $10 \pm 8.9^{\mathrm{a}}$ \\
\hline Supernatant & Intact cells with polarized membrane & $52.3 \pm 17.6^{\mathrm{a}}$ & $15.2 \pm 12^{b}$ & $79.6 \pm 2.2^{\mathrm{c}}$ \\
\hline supplemented with & Intact cells with depolarized membrane & $32.2 \pm 5.5^{\mathrm{a}}$ & $77.4 \pm 17.7^{\mathrm{b}}$ & $14.4 \pm 6.4^{\mathrm{a}}$ \\
\hline $200 \mathrm{mM}$ acetic acid & Cells with permeabilized membrane & $14.2 \pm 10.3^{\mathrm{a}}$ & $7.1 \pm 5.9^{\mathrm{a}}$ & $6 \pm 4.1^{\mathrm{a}}$ \\
\hline Supernatant & Intact cells with polarized membrane & $43.2 \pm 17.5^{\mathrm{a}}$ & $30.6 \pm 36.6^{\mathrm{a}}$ & $29.8 \pm 20.3^{\mathrm{a}}$ \\
\hline supplemented with & cells with depolarized membrane & $30.8 \pm 25.3^{\mathrm{a}}$ & $54.1 \pm 34.6^{\mathrm{a}}$ & $13.2 \pm 17.6^{\mathrm{a}}$ \\
\hline $20 \mu \mathrm{g} \mathrm{ml}^{-1}$ natamycin & Cells with permeabilized membrane & $29.4 \pm 6.2^{\mathrm{a}}$ & $8.2 \pm 1.7^{\mathrm{a}}$ & $57.1 \pm 37.9^{\mathrm{a}}$ \\
\hline
\end{tabular}

*Within a same row, mean with different letters are significantly different according to a Fisher-LSD test $(\mathrm{P}<0.05)$. 
Table 2. Intracellular $\mathrm{pH}$ of $Y$. lipolytica after incubation for 3,6 and $10 \mathrm{~d}$ in control and active supernatants and in supernatants supplemented with either $200 \mathrm{mM}$ acetic acid or $20 \mu \mathrm{g}$ $\mathrm{ml}^{-1}$ natamycin.

\begin{tabular}{|c|c|c|c|}
\hline \multirow[t]{2}{*}{ Treatments } & & \multicolumn{2}{|c|}{$\begin{array}{c}\text { Intracellular } \mathrm{pH} \text { as a function of } \\
\text { incubation time (d) }\end{array}$} \\
\hline & & 3 & 10 \\
\hline \multirow[t]{2}{*}{ Control supernatant } & First replicate & 4.94 & 5.13 \\
\hline & Second replicate & 4.9 & 5.43 \\
\hline \multirow[t]{2}{*}{ Active supernatant } & First replicate & & 5.33 \\
\hline & Second replicate & & 4.92 \\
\hline \multicolumn{4}{|c|}{ Supernatant supplemented with 200} \\
\hline mM acetic acid & & & $<3.80$ \\
\hline \multicolumn{4}{|c|}{ Supernatant supplemented with 20} \\
\hline$\mu \mathrm{g} \mathrm{ml}^{-1}$ natamycin & & $<3.80$ & 5.99 \\
\hline
\end{tabular}


Table 3. Concentrations (mM) of organic acids in control and active yogurt supernatants determined by high-performance liquid chromatograph (HPLC).

\begin{tabular}{lll}
\hline Organic acid & Control supernatant $(\mathbf{m M})$ & Active supernatant $(\mathbf{m M})$ \\
\hline Succinic acid & $1.41 \pm 0.03^{\mathrm{b} *}$ & $0.24 \pm 0.02^{\mathrm{a}}$ \\
Lactic acid & $146.21 \pm 2.57^{\mathrm{a}}$ & $235.86 \pm 1.39^{\mathrm{b}}$ \\
Acetic acid & $0.38 \pm 0.01^{\mathrm{a}}$ & $11.57 \pm 0.17^{\mathrm{b}}$ \\
2-Pyrrolidone-5-carboxylic acid & $0.06 \pm 0.00^{\mathrm{a}}$ & $0.31 \pm 0.00^{\mathrm{b}}$ \\
Hydroxyphenyllactic acid & $0.03 \pm 0.00^{\mathrm{a}}$ & $0.04 \pm 0.00^{\mathrm{b}}$ \\
L-(-)-3-phenyllactic acid & $0.01 \pm 0.00^{\mathrm{a}}$ & $0.03 \pm 0.00^{\mathrm{b}}$ \\
Hexanoic acid & nd & $1.03 \pm 0.04$ \\
2-Hydroxybenzoic acid & nd & $0.19 \pm 0.00$
\end{tabular}

*Within a same row, mean with different letters are significantly different according to a Student's t-test $(\mathrm{P}<0.05)$. nd, not detected 


\section{Figure legends}

Figure 1. (A) Assessment of $Y$. lipolytica populations in control (diamond) and active (square) yogurt supernatant ( $n=3$ for each treatment), and in yogurt supernatant supplemented with either $200 \mathrm{mM}$ acetic acid (triangle) or $20 \mu \mathrm{g} \mathrm{ml}^{-1}$ natamycin (circle) ( $n=2$ for each treatment), after incubation for $0,3,6$ and $10 \mathrm{~d}$ at $10^{\circ} \mathrm{C}$. Data are expressed as colonies forming unit (CFU) per $\mathrm{ml}$ as determined by surface-plating on PDA medium (doted lines with closed symbols) or cells per ml using a Malassez cell counting chamber (solid lines with open symbols). Bars indicate standard deviations.

(B) Proportion of $Y$. lipolytica cells with undamaged membrane after incubation for 3, 6 and $10 \mathrm{~d}$ at $10^{\circ} \mathrm{C}$ in control and active yogurt supernatants ( $n=3$ for each treatment), and in yogurt supernatants supplemented with either $200 \mathrm{mM}$ acetic acid or $20 \mu \mathrm{g} \mathrm{ml}^{-1}$ natamycin $(n=2$ for each treatment), as determined using the LIVE/DEAD BacLight viability kit followed by flow cytometry analysis. Bars indicate standard deviations. A star indicates when a treatment is significantly different from the others considering each incubation period according to a Fisher-LSD test $(P<0.05)$.

Figure 2. Proportion of $Y$. lipolytica cells producing reactive oxygen species (ROS) after incubation for 3,6 and $10 \mathrm{~d}$ at $10^{\circ} \mathrm{C}$ in control and active yogurt supernatants $(n=3$ for each treatment), and in control yogurt supernatants supplemented with $200 \mathrm{mM}$ acetic acid or 20 $\mu \mathrm{g} \mathrm{ml}^{-1}$ natamycin ( $n=2$ for each treatment). Cells were stained with dihydrorodhamine 123 dye followed by flow cytometry analysis. Bars indicate standard deviations. No significant difference was obtained between treatments considering each incubation period according to a Fisher-LSD test $(P>0.05)$. 
Figure 3. Scanning electron microscopy images of $Y$. lipolytica cells after incubation for $6 \mathrm{~d}$ at $10^{\circ} \mathrm{C}$ in (A) control and (B) active yogurt supernatants, and yogurt supernatants supplemented with either (C) $200 \mathrm{mM}$ acetic acid or (D) $20 \mu \mathrm{g} \mathrm{ml}^{-1}$ natamycin. White arrows show cells with morphological changes. 
Figure 1

A.

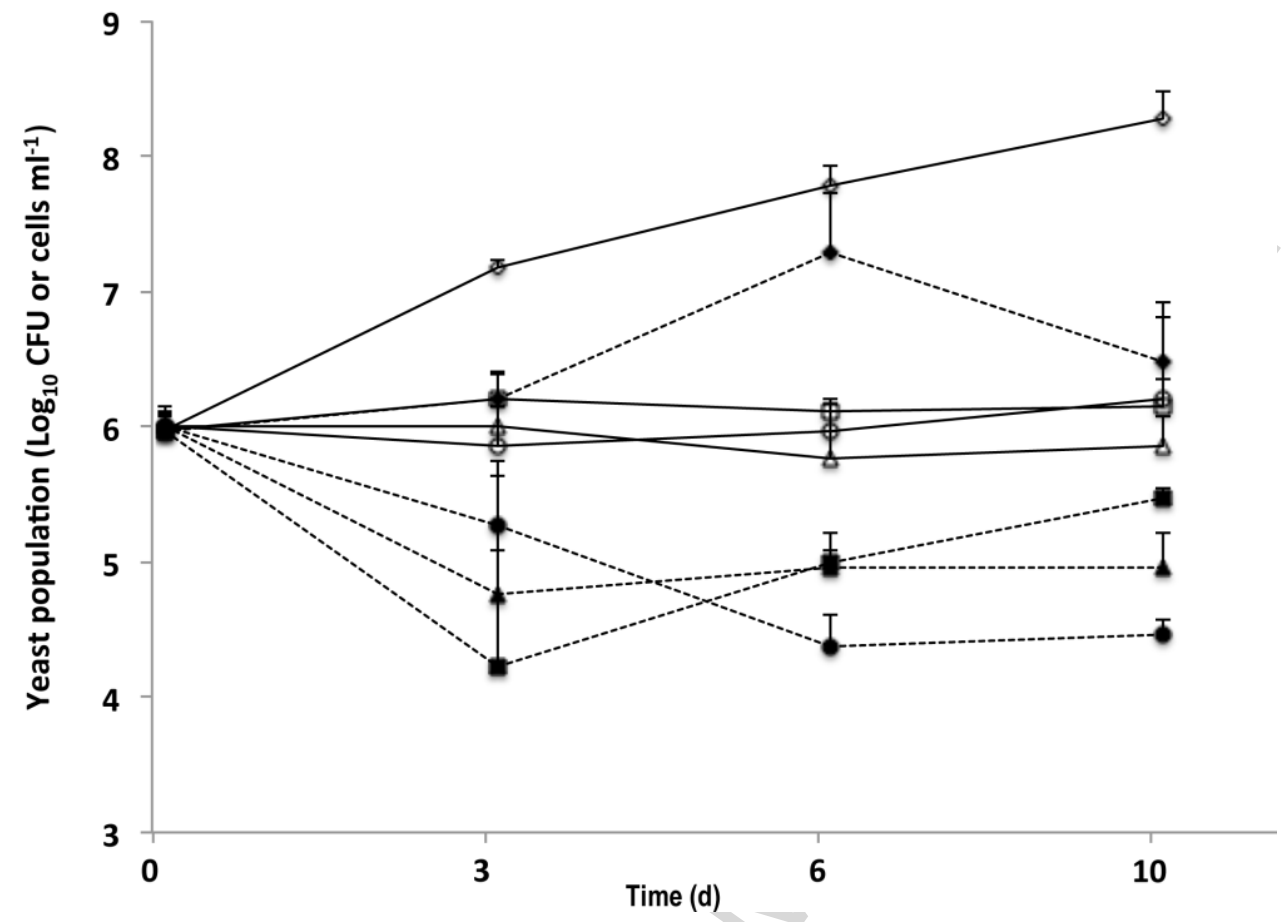

B.

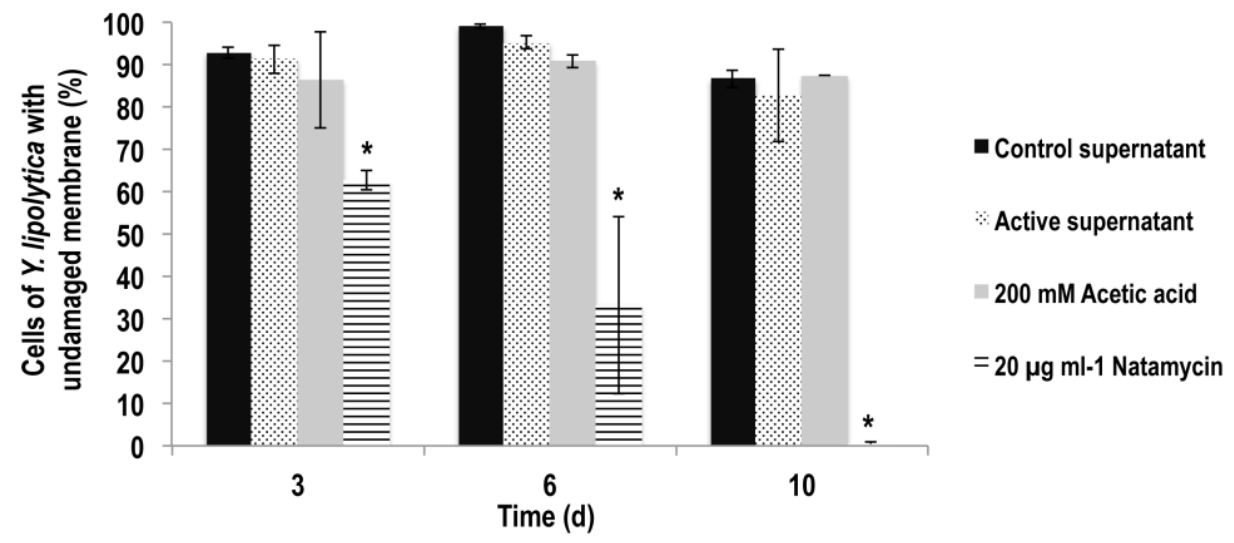


Figure 2

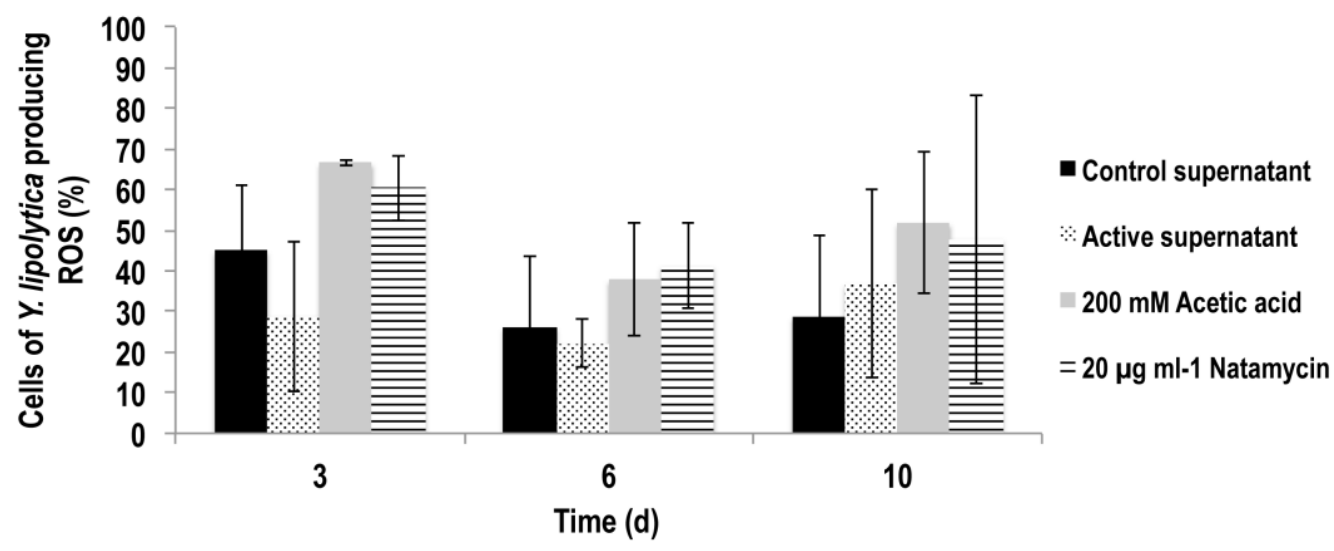




\section{Figure 3}

A

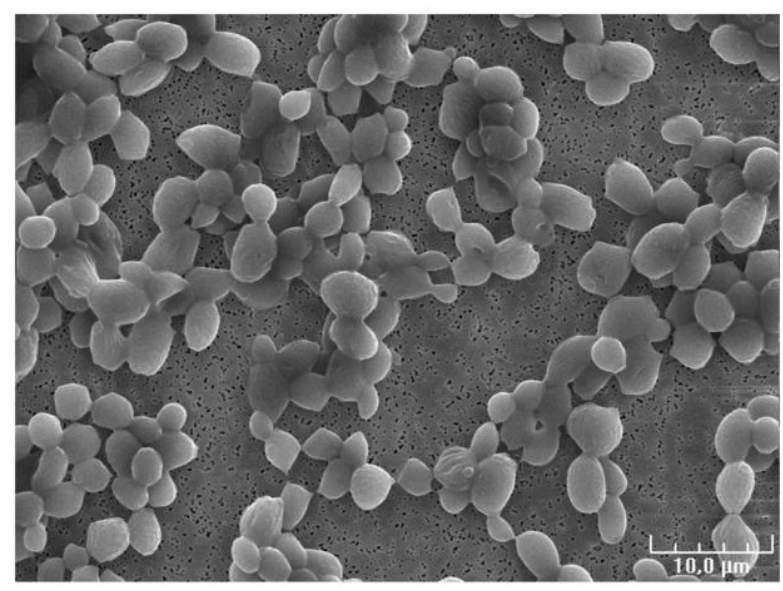

C

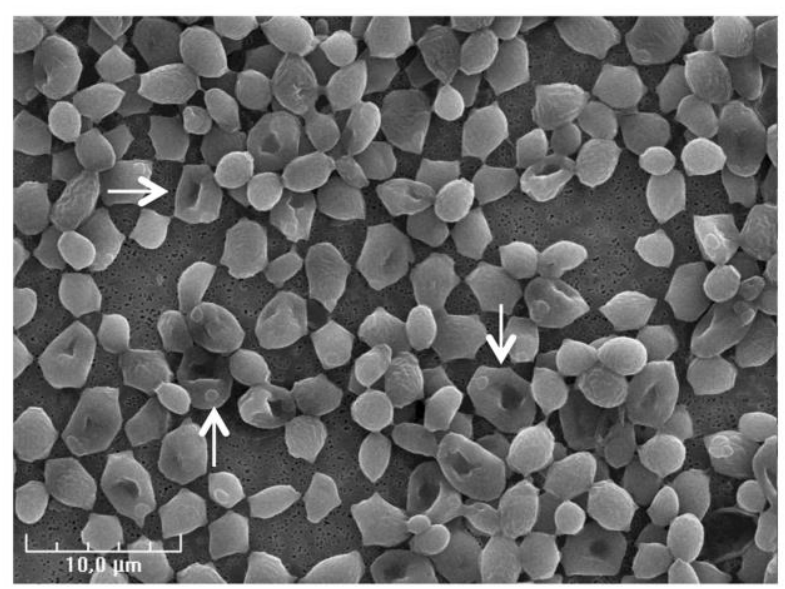

B

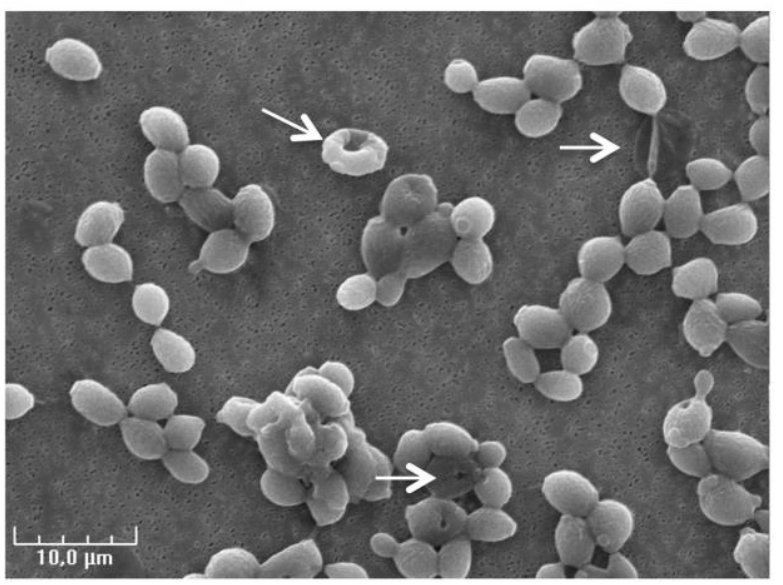

D

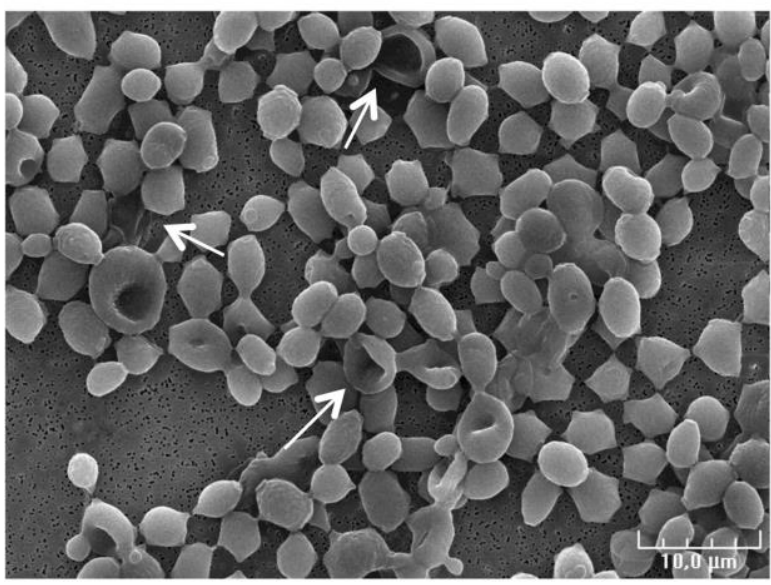

